\title{
Pharmacogenomics in osteoporosis: Steps toward personalized medicine
}

This article was published in the following Dove Press journal:

Pharmacogenomics and Personalized Medicine

9 September 2009

Number of times this article has been viewed

\section{Robert Greene' \\ Shaymaa S Mousa \\ Mohamed Ardawi \\ Mohamed Qari \\ Shaker A Mousa' \\ 'The Pharmaceutical Research Institute, Albany College of Pharmacy and Health Sciences, Albany, NY, USA; ${ }^{2}$ Center of Excellence in Osteoporosis Research, King Abdul Aziz University, Jeddah, Saudi Arabia}

Correspondence: Shaker A Mousa Executive VP and Chairman of the Pharmaceutical Research Institute, Albany College of Pharmacy and Health Sciences, One Discovery Drive, Rensselaer, NY 12144 , USA

Tel + I 5186947397

Fax +I 5186947567

Email shaker.mousa@acphs.edu
Abstract: Osteoporosis is a complicated and preventable disease with major morbidity complications that affects millions of people. In the last 15 years, there have been numerous studies and research in the new fields of pharmacogenetics and pharmacogenomics related to osteoporosis. Numerous "candidate genes" have been identified and have been found to be associated with osteoporosis as well as the treatment of osteoporosis. Many studies have found conflicting results on different polymorphisms and whether or not they are related to bone mineral density and osteoporosis. There is a need for larger and better designed pharmacogenomic studies related to osteoporosis incorporating a greater variety of candidate genes. The evaluation of osteoporosis and fracture risk is moving from a risk stratification approach to a more individualized approach, in which an individual's absolute risk of fracture is evaluable as a constellation of the individual's environmental exposure and genetic makeup. Therefore, the identification of gene variants associated with osteoporosis phenotypes or response to therapy might help individualize the prognosis, treatment, and prevention of fracture. This review focuses on major candidate genes and what needs to be done to take the genetics of osteoporosis and incorporate them into the pharmacogenomics of the management of osteoporosis.

Keywords: pharmacogenomics, osteoporosis, VDR, ER-alpha, CYP19 Gene, LRP5, COLIA1, polymorphisms, genetics

\section{Introduction}

Osteoporosis is a highly prevalent bone disorder recognized by low bone mineral density (BMD), microarchitectural deterioration of bone tissue, and enhanced bone fragility leading to an increased incidence of fracture. ${ }^{1,2}$ The likelihood of fracture is influenced by environmental factors, genetic susceptibility, biochemical markers, and by the interaction between these factors. ${ }^{1}$ Hormonal changes such as puberty and menopause also influence bone mass. ${ }^{2}$ The most serious fracture, hip fracture, occurs in approximately one in six Caucasian women, with mortality a common occurrence in the months immediately following the fracture. ${ }^{1}$ It is estimated that $30 \%-50 \%$ of women and $15 \%-30 \%$ of men with osteoporosis have a fracture at some point in their life. ${ }^{3}$ These osteoporotic fractures are associated with a two- to three-fold increase in mortality between both sexes. ${ }^{1} \mathrm{BMD}$ is one of the greatest predictors of fracture risk. ${ }^{2,4}$ However, other techniques for assessment of bone structure, including radiological measures of quantitative computerized tomography and dual photon absorptiometry have measured bone phenotype and are predictive of fracture risk. ${ }^{2}$ Despite other predictors, fracture risk increases two-fold for every standard deviation decrease in BMD. ${ }^{2,4}$ 
While environmental factors can affect BMD, it has been estimated that $45 \%$ to $80 \%$ of variance in BMD measured at the lumbar spine and femoral neck is attributable to genetic factors in twin studies. ${ }^{2,3}$

The National Osteoporosis Foundation guidelines recommend treatment to be considered for women with BMD $T$-scores below -2 with no risk factors, women with BMD $T$-scores below -1.5 and at least one risk factor for fracture, or women with a prior vertebral or hip fracture. ${ }^{5}$ There are currently several approved drug therapies for osteoporosis. The currently approved therapies include: bisphosphonates, selective estrogen receptor modulators (SERMs), estrogen replacement therapy, calcitonin, vitamin D derivatives, and parathyroid hormone. Most of these drugs act as antiresorptive agents, which work to decrease bone loss. ${ }^{1}$

Hardy and colleagues have proclaimed that this is a historic moment on the path to genomic medicine, the point at which theory is about to be translated into practice. ${ }^{6}$ Countries all over the world, especially the United Kingdom, the United States and Japan have made tremendous investments in research and development towards genomic medicine. ${ }^{4}$ In recent years, there has been an increased interest in the potential genetics and pharmacogenomics of osteoporosis and related genes. Many factors come into play when assessing someone's risk of fracture (Figure 1). Pharmacogenetics focuses on variations in single candidate genes responsible for variable drug response. However, as more discoveries are being made, a new field of pharmacogenomics has emerged looking to incorporate the entire human genome with the way drugs interact in the body. ${ }^{6}$ Testing for genetic predictors/biomarkers has the potential to improve both the safety and efficacy of drug treatment, by identifying gene candidates or appropriate doses of the drug. ${ }^{7}$

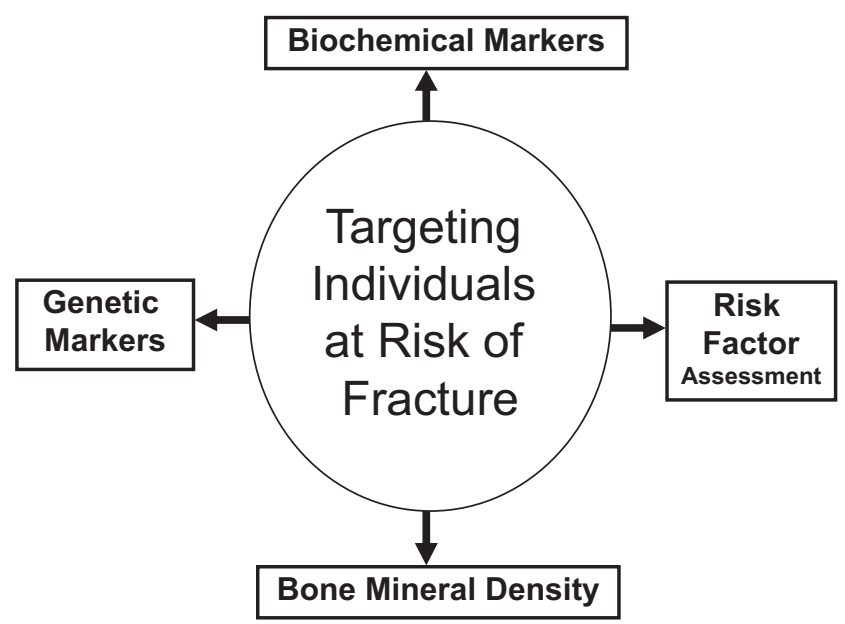

Figure I Risk factors and risk of fracture management.
Drugs interact in the body with numerous proteins, transporters, metabolizing enzymes and different types of receptors. ${ }^{2,7}$ Multiple polymorphisms or variants in certain genes could affect the drug response, requiring a search of the entire genome. ${ }^{6}$ Numerous gene polymorphisms have been found to be associated with BMD and/or fractures (Table 1). ${ }^{8}$ Polymorphisms are defined as variations of DNA sequence that are present in more than $1 \%$ of the population. Most polymorphisms are single nucleotide polymorphisms (SNPs) where individuals can differ from each other genetically by roughly 100,000 polymorphic sites, providing almost absolute variety. ${ }^{6}$ These changes in DNA sequence can occur in noncoding parts of the gene, and therefore would not be seen in the protein product. ${ }^{9}$ However, the amount of the protein product can be altered by changes in the regulatory parts of the gene which would then affect the degree of expression of the gene. ${ }^{9}$ Chromosomal regions that deviate from independent segregation with the trait and the inheritance of traits can be tracked by a technique known as linkage analysis. ${ }^{4}$ Haplotypes occur when a certain allele of one polymorphism presents on a chromosome together with another polymorphism allele to make an arrangement of alleles inherited together. ${ }^{10}$ The association between these gene polymorphisms and osteoporotic symptoms can be thoroughly detected through an analysis of haplotypes. ${ }^{10}$

Microarray gene chips such as Affymetrix GeneChip (v6, 900K; Affymetrix, Santa Clara, CA, USA) SNPs and others are an up-and-coming technology which enables the entire human genome to be scanned for relevant polymorphisms. These gene chips can also be used to identify genes which are expressed differently after a drug has been administered. ${ }^{2}$ To find out which genes are upregulated or downregulated in osteoporosis treatment can be achieved by comparing mRNA expression profiles. This is done by comparing the expression profiles in tissue taken from affected and unaffected individuals. ${ }^{2}$ Culturing human bone cells from a single individual and then comparing expression profiles after treatment such as hormone replacement therapy could prove to be very useful. ${ }^{2}$ Polymorphisms of vitamin D receptor (VDR) and estrogen receptor- $\alpha$ (ER- $\alpha)$ are key genetic determinants of bone turnover and hence bone quality. Furthermore, varying responsiveness to vitamin $\mathrm{D}$ and estrogen-based treatments may reflect allele variation in their VDR or ER- $\alpha$ signaling pathway, which might be involved in reported human differences of osteoporosis treatment responses.

The genome-wide association study (GWAS) detected two BMD candidate genes, ADAMTS18 (ADAM metalloproteinase with thrombospondin type 1 motif, 18) and TGFBR3 
Table I Pharmacogenetics and pharmacogenomics in osteoporosis

Vitamin D receptor (VDR)

- The Bsml, Apal, Taql, and Fokl polymorphisms have been extensively studied with large meta-analyses showing no association with BMD or a modest effect.

- The $\mathrm{Cdx} 2$ polymorphism was shown to have a modest effect on the risk of vertebral fracture in a meta-analysis.

\section{Estrogen receptor $(E R \alpha$ and $E R \beta)$ gene}

- The Xbal and Pvull polymorphisms have been extensively studied in the ER $\alpha$ gene.

- Meta-analyses have demonstrated association with BMD and fracture risk with the Xbal polymorphism.

- There have been inconclusive results with both polymorphisms and more research is needed.

Type I collagen (COLIAI) gene

- A polymorphism affecting the SpI binding site has been extensively studied.

- An association between fracture risk and the Spl polymorphism has been determined and backed by large meta-analyses.

- It is likely that COLIAI polymorphisms play more of a role in bone quality and fracture risk.

Aromatase (CYPI9) gene

- ATTTA repeat polymorphism has been the most extensively studied in the CYPI9 gene.

- Short TTTA alleles have been associated with lower BMD in women.

- No consistent picture of CYPI9 gene polymorphisms can be shown at present because of conflicting evidence.

Calcium-sensing receptor (CaSR) gene

- The CaSR gene A986S has been shown to have no effect in postmenopausal women related to BMD.

- Larger studies are needed but as of now there is not enough evidence proving the CaSR gene will play a major role in the pharmacogenomics of osteoporosis.

Low-density lipoprotein receptor-related protein 5 (LRP5) gene

- The variants Val667Met and Ala330Val were found to be associated with BMD and fracture risk in a meta-analysis.

- More studies are needed to determine the role of LRP5 affecting BMD and osteoporosis.

Interleukin-6 (IL-6) gene

- Functional polymorphisms in the IL-6 promoter region, -572 GC and - I74 GC were shown to be associated with markers of bone resorption in postmenopausal women.

- Larger, better studies are needed as the results are still inconclusive.

Calcitonin receptor (CTR)

- The calcitonin gene polymorphism 108 bp was found to be associated with a positive change in BMD after hormone therapy in Korean women.

- There is a lack of studies and inconclusive results with the calcitonin receptor gene and its role in the pharmacogenomics of osteoporosis.

Androgen receptor (AR) gene

- A Danish study found an association between the (CAG) repeat polymorphism in postmenopausal women with bone mass.

- There is a lack of studies and data on the androgen receptor and results are inconclusive.

$\mathrm{P}_{2} \mathrm{X}_{7}$ gene

- A loss-of-function SNP in the $\mathrm{P} \mathrm{X}_{7}$ gene has been recently discovered to play a role in osteoclast activity and bone fragility.

- The P2X $\mathrm{X}_{7}$ Glu496Ala and the Ile568Asn SNPs are associated with fracture risk and response to hormone replacement therapy.

- Larger studies are needed to determine if this gene will be useful in the pharmacogenomics of osteoporosis.

Methylenetetrahydrofolate reductase (MTHFR) gene

- The polymorphism C677T has been studied in the MTHFR gene.

- Association has been inconsistent and larger, better studies are needed in future.

Abbreviation: BMD, bone mineral density.

(transforming growth factor, beta receptor III). Replication studies verified the significant findings by GWAS, which was further confirmed to be linked to hip fracture in the Chinese sample. ${ }^{11}$ This review will look at multiple "candidate genes" with their polymorphisms and their potential effect on the pharmacogenomics of osteoporosis as well as the challenges expected in the future.

Restriction fragment length polymorphism (RFLP) is a variation in the DNA sequence of a genome that can be detected by breaking the DNA into pieces with restriction 
enzymes and analyzing the size of the resulting fragments by gel electrophoresis. Analysis of RFLP variation is an important tool in genome mapping, localization of genetic disease genes, determination of risk for a disease, genetic fingerprinting, and paternity testing.

\section{Vitamin D receptor gene}

Adequate serum vitamin D concentrations are important for the maintenance of skeletal health and calcium homeostasis. Inadequate levels of vitamin D can lead to decreased calcium absorption and serum concentration. ${ }^{12}$ The hormonal form of vitamin $\mathrm{D}$ is 1,25-dihydroxyvitamin $\mathrm{D}_{3}\left[1,25(\mathrm{OH})_{2} \mathrm{D}_{3}\right]$, which bound to the vitamin D-binding protein (DBP), can be delivered to the various vitamin $\mathrm{D}$ target cells that use the VDR to retain the hormone. ${ }^{13}$ The first gene identified to be associated with an osteoporosis-related phenotype was the VDR gene. ${ }^{14}$ Nearly 300 polymorphisms of the human VDR gene have been reported especially in the 5'-initiation and 3'-noncoding regions. ${ }^{8}$ Some of these polymorphisms, whether single alleles or as haplotypes, could modify the stability and expression level of the mRNA. ${ }^{8}$ Several RFLPs in the human VDR locus have been used in population-based studies. The most common RFLPs studied include TaqI, ApaI, BsmI, and FokI polymorphisms (Table 1). ${ }^{15}$ The BsmI polymorphism is in strong linkage disequilibrium with the ApaI and TaqI restriction fragment length polymorphisms. ${ }^{16}$ This linkage disequilibrium means that these polymorphisms coexist far more frequently than by random chance. ${ }^{16}$ Some studies suggest a relationship between the VDR alleles and risk of fracture or BMD, but others found no such association. $^{2}$

VDR's BsmI polymorphisms contain a b allele in which a study has found that among postmenopausal women who were on alendronate and hormone replacement therapy (HRT) treatments, the $b$ allele was associated with a greater increase in BMD than those carriers of the B allele..$^{2,5,17}$ Surprisingly, a separate study found that among patients taking the SERM raloxifene, the patients carrying the B allele were associated with a greater increase in BMD than the carriers of the $b$ allele. ${ }^{2,5,18}$ Although the results were the opposite for the alendronate and raloxifene, the results showed how BMD change was associated with the interaction between VDR polymorphisms and various anti-resorptive drug therapies. ${ }^{2,5}$ The association between dietary calcium intake and BMD may also be effected by the VDR gene polymorphisms. For example, in women with the VDR BB genotype, gut calcium absorption did not increase on lower dietary calcium diets. However, women with the bb genotype did have increased gut calcium absorption with less calcium intake. ${ }^{2,9,20}$ In another study, VDR gene polymorphisms and haplotypes showed a statistically significant association with BMD and more importantly with the occurrence of fractures. ${ }^{15}$ The baT haplotype with fractures appeared to be independent of the impact on the BMD in this study which suggests multiple factors contributing to fractures. ${ }^{15}$ FokI genotypes demonstrated an association with femoral neck, lumbar spine and Ward's triangle adjusted-BMD in a study with 177 Caucasian Spanish women. ${ }^{16}$ Lower femoral neck BMD was significantly lower in patients with the ff genotype than those with the FF genotype. ${ }^{16}$ Another study showed that patients carrying the TaqI $t$ allele in combination with the FokI initiation codon variant $f+t+$ carriers were less likely to sustain recurrent vertebral fractures with calcitriol therapy. ${ }^{17}$ However, Uysal and colleagues did not find significant association between ApaI and TaqI polymorphisms and osteoporosis. ${ }^{18}$

In a recent Polish study of premenopausal women with Graves' disease, women homozygous for the BAt haplotype had the lowest BMD values in the femoral neck. However, the results were not statistically significant and their conclusions showed that the BsmI, ApaI, TaqI, and FokI polymorphisms of the VDR gene did not predict the risk of decreased BMD in young women. ${ }^{10}$ On top of that, the FokI polymorphism and the BsmI-ApaI-TaqI haplotypes were found to have no effect on either BMD or fracture risk in a large scale 2006 meta-analysis. ${ }^{16}$ This contradicts previous claims that these polymorphisms (BsmI, ApaI, TaqI, and FokI) act as genetic determinants of BMD. ${ }^{16}$ For these polymorphisms, genotyping error has been documented in studies, as well as significant but downsized genetic effects in meta-analyses of small studies. ${ }^{16}$ However, this large-scale meta-analysis did find evidence for a modest effect of the $\mathrm{Cdx} 2$ polymorphism on risk for vertebral fracture. ${ }^{16}$ Previous studies did indicate that the VDR Cdx2 polymorphism is a functional variant that influences DNA protein binding and gene transcription. ${ }^{16}$ A number of biological endpoints related to osteoporosis seem to be influenced by certain VDR gene variants. However, judging from the multitude of studies, the associations have different magnitudes with BMD and probably have very weak effects. ${ }^{19}$ Hence, the effect of the VDR gene on osteoporosis appears to be positive but the magnitude is rather small. ${ }^{13}$ The unique interactions of genetic background and environmental factors may explain the different and sometimes conflicting results regarding prediction of BMD by VDR genotypes. ${ }^{20}$ Besides the vitamin $\mathrm{D}$ receptor, the vitamin D-binding protein (DBP) has also been studied 
in relation to BMD and fractures. Al-oanzi and colleagues found that a DBP gene microsatellite polymorphism may exert influence on the pathogenesis of osteoporosis in men. ${ }^{21}$ Although studies have shown conflicting results with certain VDR polymorphisms, positive results with the $\mathrm{Cdx} 2$ and certain haplotypes do not go unnoticed and future discoveries are likely to be made. It is important however, to realize that masses of studies have been performed on the BsmI, ApaI, TaqI, and FokI polymorphisms and the focus should be on the discovery of new polymorphisms related to osteoporosis.

\section{Estrogen receptor (ER) gene}

Important candidate markers of the risk for osteoporosis include the genes encoding for estrogen receptors ER $\alpha$ (ESR1) and ER $\beta$ (ESR2) see Table $1 .{ }^{14} \mathrm{ER} \alpha$ and ER $\beta$ are both expressed in osteoblasts, osteoclasts and bone marrow stromal cells. ${ }^{22}$ Estrogens exert beneficial effects on the development and maintenance of the skeleton, in women and in men. ${ }^{22}$ The two marker loci, the XbaI and PvuII polymorphisms are generally the gold-standard for studies involving the ER $\alpha$ gene (Table 1). ${ }^{23}$ The association with $\mathrm{BMD}$, bone loss and fractures have been analyzed in great detail with the ESR1 gene polymorphisms encoding for ER $\alpha .{ }^{8}$ A meta-analysis of 5,000 women from 22 studies concluded that the carriers of the XX genotype in the XbaI polymorphism have a significantly higher BMD at lumbar spine or hip compared to the $\mathrm{xx}$ genotype. ${ }^{9,30}$ A separate recent meta-analysis in 18,917 individuals from eight European centers found evidence of association with fracture risk in the ESR1 polymorphism, but not with BMD..$^{9,31}$ It was found that the absence of $\mathrm{XbaI}$ polymorphism recognition site equaled a risk reduction in all fractures of $19 \%$ while the risk reduction in all vertebral fractures was 35\%. ${ }^{31,32}$ These studies and meta-analyses suggest that ESR1 genetic variation plays a role in bone structure and bone strength. ${ }^{8}$ A Finnish cohort study showed that the P allele in the PvuII polymorphism was significantly associated with the reduction in the incidence of new fractures in the group treated with HRT. However, the PvuII polymorphism was not significantly associated with fracture risk in the non-HRT group. ${ }^{29,33}$ Another study found that in Thai postmenopausal women without the $\mathrm{P}$ allele, the increase in vertebral $\mathrm{BMD}$ responding to estrogen therapy was significantly lower compared to those with the P allele. ${ }^{29,34}$ However, a Spanish study of postmenopausal women found no association of the PvuII or XbaI ER $\alpha$ polymorphisms with BMD in any localization. ${ }^{16}$ A few studies also reported associations of ESR1 genotypes with BMD in men, but the majority found no association. ${ }^{8}$
An association has also been reported between a TA repeat polymorphism in the ER promoter and bone mass in both Japanese and US populations. ${ }^{24}$

Association studies with BMD and fracture risk relating to the polymorphism in the estrogen receptor $\beta$ (ER $\beta)$ have only been done a few times. ${ }^{8}$ These studies mostly focused on the number of CA repeats and were mostly done in postmenopausal women. ${ }^{8}$ A significant association of femoral BMD in both men and women with the CA repeat was found in one cohort, as well as two other polymorphisms (rs1256031 and rs1256059) that were associated with femur neck BMD exclusively in men. ${ }^{935}$ Although there is conflicting evidence, the large meta-analyses did show promising results with the $\mathrm{XbaI}$ polymorphisms, as well as some evidence with the PvuII polymorphisms. However, more studies are needed to make solid conclusions.

\section{Type I collagen (COLIAI) gene}

One of the major proteins in bone is type I collagen. ${ }^{13}$ Differences in bone density and fracture risk in a large number of osteoporosis studies have been associated with a polymorphism affecting an Sp1 binding site in the first intron of the collagen $1 \alpha 1$ gene (Table 1$){ }^{2}$ The binding site for the transcription factor $\mathrm{Sp} 1$ is modified, which results in a subtle change in the equilibrium between $\alpha 1$ and $\alpha 2$ chains in the triple helix. ${ }^{8}$ Increased amounts of the collagen $1 \alpha 1$ chain were produced from cultured osteoblasts carrying the Ss heterozygote genotype because the s allele had greater affinity for transcription factor $\mathrm{Sp} 1$ than the $\mathrm{S}$ allele. ${ }^{23}$ In a Spanish study, the three genotypes ss, Ss and SS of the COLIA1-Sp1 gene did not show any statistically significant differences in lumbar spine, femoral neck and Ward's triangle BMD. ${ }^{16}$ However, they did find a statistically significant association between the Sp1 polymorphism and the subjects' personal history of fractures. The ss group actually had 2.7 times the risk of the SS group of having suffered a fracture in this 177 women study. ${ }^{16}$

A higher prevalence of fractures among heterozygote's Ss and homozygote's ss compared to the SS genotype was confirmed in a large cohort study and a meta-analysis., , $36,37^{9}$ However, these studies found that the COLIA1 alleles were better associated with fracture risk itself than BMD, which is positive because the ultimate goal is reducing fractures in osteoporosis. ${ }^{9,36,37}$ These results were only partially confirmed in a meta-analysis of several European cohorts (GENOMOS). ${ }^{9,38}$ The GENOMOS study concluded that the COLIA1 Sp1 polymorphism could predispose women to vertebral fractures independent of $\mathrm{BMD}$, and is modestly 
associated with reduced BMD. ${ }^{38}$ Carriers of the Sp1 SS genotype showed an association with increased femoral neck BMD in another study on 108 peri-menopausal women with osteopenia; however the BMD was decreased in those carrying the s allele. ${ }^{5,39}$

A recent study of haplotypes of promoter and intron 1 polymorphisms in the COLIA1 gene investigated the effects of three polymorphisms in the COLIA1-gene. ${ }^{25}$ It was found that the $+1245 \mathrm{~T}$ allele, the -1663 del allele, and haplotype 2 were associated with a reduced BMD while haplotype 1 was associated with an increased BMD. ${ }^{25}$ An increased risk of vertebral fractures partly independently of BMD was found with the $-1997 \mathrm{~T}$ allele and haplotype $3{ }^{25}$ These findings show that these polymorphisms influence gene expression and it is likely that the polymorphism may be more related to bone quality rather than quantity. ${ }^{14,40}$ However, the results look promising with the COLIA1 gene polymorphisms as the ultimate goal in osteoporosis should be to reduce the number of fractures. The recent discovery of new polymorphisms in the COLIA1 gene also show us that we can still make discoveries and find new alleles that influence BMD and the osteoporosis phenotype.

\section{CYPI 9 gene}

The key enzyme catalyzing the conversion of androstenedione to estrone and testosterone to estradiol is the CYP19 gene, also known as aromatase. ${ }^{22}$ Aromatase knockout mice have exhibited bone loss and inactivating mutations have lead to decreased BMD in humans. ${ }^{22}$ A total number of 654 SNPs are linked to the CYP19A1 gene in the National Center for Biotechnology Information database and 193 SNPs in the HapMap database. ${ }^{26}$ Polymorphisms in the CYP19 gene in several studies have been reported, but the conclusions have been inconsistent. ${ }^{22}$ A TTTA repeat sequence polymorphism situated in intron 4 has been the most widely studied (Table 1). ${ }^{26}$ The TTTA repeat polymorphism of CYP19 has been reported to be associated with higher circulating estradiol and higher BMD at hip and lumbar spine. ${ }^{32,42}$ Most authors have found an association between short TTTA alleles and lower BMD in postmenopausal women. However, the results have fluctuated with other studies, one study even found higher BMD in women with short TTTA alleles. ${ }^{41,42}$ Male subjects have shown similar results in studies involving the CYP19 gene. ${ }^{26}$ One study found that in men aged over 45 years, short alleles were associated with lower BMD at the spine and total hip. However, there was no association in younger men between BMD and aromatase genotype. ${ }^{41,43}$ Although aromatase is considered an important player in the development of osteoporosis, no consistent picture of CYP19 gene polymorphisms can be shown at present. ${ }^{22}$ The CYP19 gene is another gene in which more research needs to occur so that a clearer picture arises with its role in osteoporosis.

\section{Calcium-sensing receptor gene}

The calcium-sensing receptor ( $\mathrm{CaSR}$ ) belongs to the G-protein coupled receptor super-family and serves as a sensor of the extracellular calcium levels in different tissues. ${ }^{26}$ This receptor plays a key role in the regulation of secretion of parathyroid hormone and calcitonin. ${ }^{26}$ An analysis of polymorphisms of the CaSR gene in a Canadian population found a significant correlation with extracellular calcium levels. ${ }^{20}$ An Israeli study found that among low BMD subjects, femoral neck BMD differed between homozygous and heterozygous CaSR genotype carriers. ${ }^{26}$ However, another study on the a variant of the CaSR gene A986S found no effect in postmenopausal women at baseline or in response to calcium supplementation (Table 1). ${ }^{44}$ A Hungarian study also found that no significant effect of CaSR genotype on BMD was observed either in the whole population or in the subgroups. ${ }^{45}$ Their data does not support the idea that CaSR gene A986S polymorphism has an impact on bone mass. ${ }^{45}$ Larger studies are ultimately needed and the search for more polymorphisms should also continue with the CaSR gene. CASR gene is upregulated by pro-inflammatory cytokines, which might contribute to altered extracellular calcium homeostasis in the critically ill.

\section{Low-density lipoprotein receptor-related protein 5}

The low-density lipoprotein receptor-related protein 5 (LRP5) has been found to be linked to high bone mass. A mis-sense mutation (G171V) was found in a family study of individuals with exceptionally high BMD but the participants were otherwise phenotypically normal. ${ }^{1}$ Autosomal dominant high bone mass and autosomal recessive osteoporosis psuedoglioma syndrome are two disorders which have been found to be associated with the LRP5 gene. ${ }^{13}$ However, before the discovery of LRP5 being linked to these bone disorders, it was previously unknown to play a role in bone metabolism. ${ }^{13}$ Another recent family study associated increased BMD with six novel mutations in LRP5 among 13 confirmed polymorphisms. ${ }^{2,46}$ Two common variants (Val667Met and Ala1330Val) in the LRP5 gene were found to be associated with BMD and fracture risk in a recent metaanalysis (Table 1). ${ }^{5,47}$ Carriers of the MetMet genotype of the Val667Met variant were associated with $20 \mathrm{mg} / \mathrm{cm}^{2}$ lower 
in lumbar spine BMD and $11 \mathrm{mg} / \mathrm{cm}^{2}$ lower in femoral neck BMD compared with those with MetVal and ValVal genotypes. ${ }^{5,47}$ There was $16 \mathrm{mg} / \mathrm{cm}^{2}$ lower in lumbar spine BMD and $10 \mathrm{mg} / \mathrm{cm}^{2}$ lower in femoral neck BMD in the ValVal genotype in the Ala1330Val variant compared to those with AlaVal and AlaAla genotypes. ${ }^{5,47}$ This large meta-analysis is promising and should encourage more studies in the future of the LRP5 gene polymorphisms.

Common LRP5 variants may affect osteoporosis risk in the general population. Recent study generated large-scale evidence on whether two common variants of LRP5 (Val667Met, Ala1330Val) and one variant of LRP6 (Ile1062 Val) are associated with BMD and fracture risk or not. In this investigation, haplotype analysis indicated that Met667 and Val1330 variants both independently affected BMD. The LRP6 Ile1062Val polymorphism was not associated with any osteoporosis phenotype. All associations except that between Val1330, all fractures and vertebral fractures remained significant after multiple-comparison adjustments. In conclusion, common LRP5 variants are consistently associated with BMD and fracture risk across different white populations. ${ }^{46}$

\section{Interleukin-6}

Interleukin-6 (IL-6) is an inflammatory cytokine, whose production is increased after menopause. The IL-6 gene locus has been linked to BMD in postmenopausal women in several studies. ${ }^{8}$ These studies suggest that the variation in the rate of bone loss following estrogen deprivation could be influenced by the IL-6 polymorphisms. ${ }^{8}$ Functional polymorphisms in the IL-6 promoter region, -572 GC and -174 GC, were shown to be associated with markers of bone resorption in postmenopausal women (Table 1). ${ }^{9,48}$ In women who were either more than 15 years postmenopause, estrogen deficient, or who had insufficient calcium intake, a cohort found BMD to be significantly lower with the IL-6 genotype -174GG compared to CC, and intermediate with GC. ${ }^{9,49}$ Modulating the response of the skeleton to estrogen deficiency as well as influencing bone remodeling is a likely possibility for the IL-6 gene promoters. ${ }^{8}$ Larger, better designed studies are needed to better understand the impact the IL- 6 genotypes have on osteoporosis.

\section{Calcitonin receptor}

A member of the transmembrane receptor family, the calcitonin receptor (CTR) has been studied in relation to pharmacogenomics in osteoporosis. A point mutation polymorphism $(\mathrm{C}->\mathrm{T}$ has been identified in the 3 '-region of the calcitonin receptor gene which included a Pro $->$ Leu shift in the third intracellular domain of the protein. ${ }^{16}$ This polymorphism has been found to be associated with lumbar $\mathrm{BMD}$ and is recognized by the Alu I restriction enzyme. ${ }^{16}$ In another Korean study, the calcitonin gene (CA) polymorphism $108 \mathrm{bp}$ was found to be associated with a positive change of BMD at the femoral neck after hormone therapy (Table 1). ${ }^{50}$ Again, more research is needed to fully understand the effects of gene polymorphisms on the calcitonin receptor.

\section{Androgen receptor gene}

Androgens, after aromatization to estrogens, most likely have an indirect positive effect on bone. ${ }^{22} \mathrm{~A}$ microsatellite repeat polymorphism in exon 1 of the AR gene has been reported in several studies. ${ }^{22}$ The ability of the receptor to activate transcription of target genes is inversely associated with the length of the encoded polymorphic polyglutamate tract. ${ }^{22}$ Both sexes have shown a presence of long alleles which has been related to BMD. ${ }^{22}$ A Danish study found that the $(\mathrm{CAG})_{n}$ repeat polymorphism in postmenopausal women with high blood levels of sex hormone-binding globulin was associated with bone mass (Table 1). ${ }^{28,51}$ There is very limited data on the androgen receptor gene and osteoporosis. More studies are clearly needed to determine whether this gene play a role.

\section{$P 2 X_{7}$ gene}

The purinergic $\mathrm{P} 2 \mathrm{X}_{7}$ receptor is a ligand-gated cation channel which may play important roles in regulation of osteoclast generation and survival. ${ }^{52}$ A 2007 study for the first time provided evidence that a loss-of-function SNP in the $\mathrm{P}_{2} \mathrm{X}_{7}$ gene is clearly affecting osteoclast activity and bone fragility. ${ }^{52}$ Postmenopausal women with the P2X $\mathrm{X}_{7}$ Glu496Ala and the Ile568Asn single nucleotide polymorphisms are associated with 10-year fracture risk and response to hormone replacement therapy treatment (Table 1). ${ }^{52}$ In addition, it was determined the Glu496Ala polymorphism is strongly influencing osteoclast apoptosis in vitro, which could contribute to increased fracture risk. ${ }^{52}$ This is an intriguing candidate whose fairly recent discovery deserves future study.

\section{Methylenetetrahydrofolate reductase gene}

A common allelic polymorphism C677T in the methylenetetrahydrofolate reductase (MTHFR) gene results in an enzyme which is more thermolabile and causes higher homocysteine and lower folate levels (Table 1). ${ }^{13}$ The polymorphism has been found to be associated with BMD or fractures in a 
number of studies. Lower broadband ultrasound attenuation and lower BMD at the Ward's triangle were found in one study whose subjects had the TT genotype. ${ }^{14,53}$ However, the association of the MTHFR gene with BMD and fractures has been inconsistent. A long-term interventional study taking into account the nutrient-gene interaction is needed. ${ }^{13}$

\section{Integrin beta3 Leu33Pro polymorphism}

Individuals homozygous for the integrin beta3 Leu33Pro polymorphism have a two-fold risk of hip fracture, mainly confined to postmenopausal women. Integrin beta3 Leu33Pro homozygosity could prove a useful marker for risk of future hip fracture and may contribute to pharmacogenetic variation in effects of integrin alphavbeta3 antagonists. ${ }^{54}$

\section{Conclusions}

Pharmacogenomics will likely revolutionize the medical and pharmaceutical world. However, when dealing with the pharmacogenomics of osteoporosis, painstaking research must first be done to identify exactly which genes out of the entire human genome play a role in the disease. This review has briefly discussed a multitude of potential gene candidates. A majority of the research focused on the VDR, the ER $\alpha$, and the type I collagen gene. However, there are several other candidate genes that should be examined. As more discoveries are being made, it is becoming clear that a single gene candidate is probably not going to predict whether a patient develops osteoporosis or responds to treatment for osteoporosis. It is more likely going to be a combination of several gene polymorphisms in an individual's genetic makeup. Regardless, pharmacogenomics in osteoporosis is coming, it's just a matter of when. There needs to be a concerted effort across the board for funding, research, and new technology to bring the information to where it can be used clinically. There is a need for larger, better defined studies that bridge the gap between discovery and development of ways to use this information.

\section{Future perspectives}

It is difficult to say whether or not we are at the point of using the pharmacogenomics of osteoporosis in clinical practice. However, it is more than likely that we are still years away from this individualized medicine approach with osteoporosis. Astounding research has been accomplished in the last 15 years in identifying gene candidates as markers for osteoporosis. We need a unified front once we have conclusive results of which genes impact osteoporosis the most.
There needs to be much larger studies to take this information and incorporate it into clinical practice.

The process of bringing the pharmacogenomics of osteoporosis to the physician's office will likely be a long one. Besides the advantages and opportunities, there are several challenges that must first be overcome. One of the first challenges will be the pharmacoeconomic aspect of this new technology. Osteoporosis affects a large number of people from every spectrum of the socioeconomic scale. State and federal assistance programs will be faced with tough decisions on whether to include such technology on their formularies. Large pharmacoeconomic studies will be needed to determine whether or not such technology will be cost effective. Besides the cost issue, there are numerous ethical concerns as well. The largest being the issue of personal privacy. In the last few years, personal health information on hundreds of thousands of people has been compromised because of security lapses at hospitals, insurance companies and government agencies. There is strong opposition to the current plan of computerizing all of the US citizens' medical records due to privacy concerns. It is possible that the introduction of genomic medicine will face an even stronger opposition. If this were the case, there would need to be stronger legislation and regulations against the misuse of personal information.

\section{Disclosures}

The authors report no conflicts of interest in this work.

\section{References}

1. Stewart TL, Jin H, McGuigan FE, et al. Haplotypes defined by promoter and intron 1 polymorphisms of the COLIA1 gene regulate bone mineral density in women. J Clin Endocrinol Metab. 2006;91(9):3575-3583.

2. Nguyen TV, Eisman JA. Pharmacogenomics of osteoporosis: opportunities and challenges. J Musculoskelet Neuronal Interact. 2006;6(1):62-72.

3. Eisman JA, Pharmacogenetics of the vitamin D receptor and osteoporosis. Drug Metab Dispos. 2001;29(4 Pt 2):505-512.

4. Nguyen TV, Center JR, Eisman JA. Pharmacogenetics of osteoporosis and the prospect of individualized prognosis and individualized therapy. Curr Opin Endocrinol Diabetes Obes. 2008;15(6):481-488.

5. Deal C. Potential new drug targets for osteoporosis. Nat Clin Pract Rheum. 2009;5(1):20-27.

6. Hardy BJ, Seguin B, Goodsaid F, Jimenez-Sanchez G, Singer PA, Daar AS. The next steps for genomic medicine: challenges and opportunities for the developing world. Nat Rev Genet. 2008;9(Suppl 1):S23-S27.

7. Sadee W. Pharmacogenomics. West J Med. 1999;171(5-6):328-332.

8. Haga SB, Burke W. Pharmacogenetic testing: not as simple as it seems. Genet Med. 2008;10(6):391-395.

9. Ferrari S. Human genetics of osteoporosis. Best Pract Res Clin Endocrinol Metab. 2008;22(5):723-735.

10. Valdivielso JM, Fernandez E. Vitamin D receptor polymorphisms and diseases. Clin Chim Acta. 2006;371(1-2):1-12.

11. Xiong DH, Liu XG, Guo YF, et al. Genome-wide association and follow-up replication studies identified ADAMTS18 and TGFBR3 as bone mass candidate genes in different ethnic groups. Am J Hum Genet. 2009;84(3):388-398. 
12. Horst-Sikorska W, Ignaszak-Szczepaniak M, Marcinkowska M, Kaczmarek M, Stajgis M, Slomski R. Association analysis of vitamin $\mathrm{D}$ receptor gene polymorphisms with bone mineral density in young women with Graves' disease. Acta Biochim Pol. 2008;55(2): 371-380.

13. Haussler MR, Haussler CA, Bartik L, et al. Vitamin D receptor: molecular signaling and actions of nutritional ligands in disease prevention. Nutr Rev. 2008;66(Suppl 2):S98-S112.

14. Ongphiphadhanakul B. Osteoporosis: the role of genetics and the environment. Forum Nutr. 2007;60:158-167.

15. Massart F, Marcucci G, Brandi ML. Pharmacogenetics of bone treatments: the VDR and ERalpha gene story. Pharmacogenomics. 2008;9(6):733-746.

16. Uitterlinden AG, Ralston SH, Brandi ML, et al. The association between common vitamin $\mathrm{D}$ receptor gene variations and osteoporosis: a participant-level meta-analysis. Ann Intern Med. 2006;145(4): 255-264.

17. Palomba S, Numis FG, Mossetti G, et al. Effectiveness of alendronate treatment in postmenopausal women with osteoporosis: relationship with BsmI vitamin D receptor genotypes. Clin Endocrinol (Oxf). 2003;58(3):365-371.

18. Palomba S, Numis FG, Mossetti G, et al. Raloxifene administration in post-menopausal women with osteoporosis: effect of different BsmI vitamin D receptor genotypes. Hum Reprod. 2003;18(1):192-198.

19. Ongphiphadhanakul B, Rajatanavin R, Chanprasertyothin S, et al. Vitamin D receptor gene polymorphism is associated with urinary calcium excretion but not with bone mineral density in postmenopausal women. J Endocrinol Invest. 1997;20(10):592-596.

20. Dawson-Hughes B, Harris SS, Finneran S. Calcium absorption on high and low calcium intakes in relation to vitamin D receptor genotype. J Clin Endocrinol Metab. 1995;80(12):3657-3661.

21. Horst-Sikorska W, Kalak R, Wawrzyniak A, Marcinkowska M, Celczynska-Bajew L, Slomski R. Association analysis of the polymorphisms of the VDR gene with bone mineral density and the occurrence of fractures. J Bone Miner Metab. 2007;25(5):310-319.

22. Bandres E, Pombo I, Gonzalez-Huarriz M, Rebollo A, Lopez G, GarciaFoncillas J. Association between bone mineral density and polymorphisms of the VDR, ERalpha, COL1A1 and CTR genes in Spanish postmenopausal women. J Endocrinol Invest. 2005;28(4):312-321.

23. Morrison NA, George PM, Vaughan T, Tilyard MW, Frampton CM, Gilchrist NL. Vitamin D receptor genotypes influence the success of calcitriol therapy for recurrent vertebral fracture in osteoporosis. Pharmacogenet Genomics. 2005;15(2):127-135.

24. Uysal AR, Sahin M, Gursoy A, Gullu S. Vitamin D receptor gene polymorphism and osteoporosis in the Turkish population. Genet Test. 2008;12(4):591-594.

25. Uitterlinden AG, Fang Y, Bergink AP, van Meurs JB, van Leeuwen HP, Pols HA. The role of vitamin D receptor gene polymorphisms in bone biology. Mol Cell Endocrinol. 2002;197(1-2):15-21.

26. Eckstein M, Vered I, Ish-Shalom S, et al. Vitamin D and calciumsensing receptor genotypes in men and premenopausal women with low bone mineral density. Isr Med Assoc J. 2002;4(5):340-344.

27. Al-oanzi ZH, Tuck SP, Mastana SS, et al. Vitamin D-binding protein gene microsatellite polymorphism influences BMD and risk of fractures in men. Osteoporos Int. 2008;19(7):951-960.

28. Thijssen JH. Gene polymorphisms involved in the regulation of bone quality. Gynecol Endocrinol. 2006;22(3):131-139.

29. Xiong DH, Long JR, Recker RR, Deng HW. Pharmacogenomic approaches to osteoporosis. Pharmacogenomics J. 2003;3(5): 261-263.

30. Ioannidis JP, Stavrou I, Trikalinos TA, et al. Association of polymorphisms of the estrogen receptor alpha gene with bone mineral density and fracture risk in women: a meta-analysis. $J$ Bone Miner Res. 2002;17(11):2048-2060.

31. Ioannidis JP, Ralston SH, Bennett ST, et al. Differential genetic effects of ESR1 gene polymorphisms on osteoporosis outcomes. JAMA. 2004;292(17):2105-2114.
32. Williams FM, Spector TD. The genetics of osteoporosis. Acta Reumatol Port. 2007;32(3):231-240

33. Salmen T, Heikkinen AM, Mahonen A, et al. The protective effect of hormone-replacement therapy on fracture risk is modulated by estrogen receptor alpha genotype in early postmenopausal women. J Bone Miner Res. 2000;15(12):2479-2486.

34. Ongphiphadhanakul B, Chanprasertyothin S, Payatikul P, et al. Oestrogen-receptor-alpha gene polymorphism affects response in bone mineral density to oestrogen in post-menopausal women. Clin Endocrinol (Oxf). 2000;52(5):581-585.

35. Shearman AM, Karasik D, Gruenthal KM, et al. Estrogen receptor beta polymorphisms are associated with bone mass in women and men: the Framingham Study. J Bone Miner Res. 2004;19(5):773-781.

36. Uitterlinden AG, Burger H, Huang Q, et al. Relation of alleles of the collagen type Ialphal gene to bone density and the risk of osteoporotic fractures in postmenopausal women. $N$ Engl $J$ Med. 1998;338(15):1016-1021.

37. Mann V, Hobson EE, Li B, et al. A COL1A1 Sp1 binding site polymorphism predisposes to osteoporotic fracture by affecting bone density and quality. J Clin Invest. 2001;107(7):899-907.

38. Ralston SH, Uitterlinden AG, Brandi ML, et al. Large-scale evidence for the effect of the COLIA1 Sp1 polymorphism on osteoporosis outcomes: the GENOMOS study. PLoS Med. 2006;3(4):e90.

39. Qureshi AM, Herd RJ, Blake GM, Fogelman I, Ralston SH. COLIA1 Sp1 polymorphism predicts response of femoral neck bone density to cyclical etidronate therapy. Calcif Tissue Int. 2002;70(3):158-163.

40. Husted LB, Harslof T, Gonzalez-Bofill N, et al. Haplotypes of promoter and intron 1 polymorphisms in the COLIA1 gene are associated with increased risk of osteoporosis. Calcif Tissue Int. 2009;84(2):85-96.

41. Riancho JA. Polymorphisms in the CYP19 gene that influence bone mineral density. Pharmacogenomics. 2007;8(4):339-352.

42. Dick IM, Devine A, Prince RL. Association of an aromatase TTTA repeat polymorphism with circulating estrogen, bone structure, and biochemistry in older women. Am J Physiol Endocrinol Metab. 2005;288(5):E989-E995.

43. Zarrabeitia A, Zarrabeitia MT, Valero C, Gonzalez-Macias J, Riancho JA. Age-related influence of common aromatase gene polymorphisms on bone mass of healthy men. Bone. 2004;35(1):243-248.

44. Young R, Wu F, Van de Water N, Ames R, Gamble G, Reid IR. Calcium sensing receptor gene A986S polymorphism and responsiveness to calcium supplementation in postmenopausal women. J Clin Endocrinol Metab. 2003;88(2):697-700.

45. Takacs I, Speer G, Bajnok E, et al. Lack of association between calciumsensing receptor gene "A986S" polymorphism and bone mineral density in Hungarian postmenopausal women. Bone. 2002;30(6):849-852.

46. van Meurs JB, Trikalinos TA, Ralston SH, et al; GENOMOS Study. Large-scale analysis of association between LRP5 and LRP6 variants and osteoporosis. JAMA. 2008;299(11):1277-1290.

47. International HapMap Consortium. The International HapMap Project. Nature. 2003;426(6968):789-796.

48. Ferrari SL, Garnero P, Emond S, Montgomery H, Humphries SE, Greenspan SL. A functional polymorphic variant in the interleukin-6 gene promoter associated with low bone resorption in postmenopausal women. Arthritis Rheum. 2001;44(1):196-201.

49. Ferrari SL, Karasik D, Liu J, et al. Interactions of interleukin-6 promoter polymorphisms with dietary and lifestyle factors and their association with bone mass in men and women from the Framingham Osteoporosis Study. J Bone Miner Res. 2004;19(4):552-559.

50. Kim JG, Choi YM, Moon SY, Lee JY. Association of the calcitonin gene (CA) polymorphism with bone mass and bone responsiveness to hormone therapy in postmenopausal Korean women. Menopause. 2003;10(6):544-549.

51. Tofteng CL, Kindmark A, Brändström H, et al; Danish Osteoporosis Prevention Study. Polymorphisms in the CYP19 and AR genes - relation to bone mass and longitudinal bone changes in postmenopausal women with or without hormone replacement therapy: The Danish Osteoporosis Prevention Study. Calcif Tissue Int. 2004;74(1):25-34. 
52. Ohlendorff SD, Tofteng CL, Jensen JE, et al. Single nucleotide polymorphisms in the $\mathrm{P} 2 \mathrm{X} 7$ gene are associated to fracture risk and to effect of estrogen treatment. Pharmacogenet Genomics. 2007;17(7):555-567.

53. McLean RR, Karasik D, Selhub J, et al. Association of a common polymorphism in the methylenetetrahydrofolate reductase (MTHFR) gene with bone phenotypes depends on plasma folate status. $J$ Bone Miner Res. 2004;19(3):410-418.
54. Tofteng CL, Bach-Mortensen P, Bojesen SE, Tybjaerg-Hansen A, Hyldstrup L, Nordestgaard BG. Integrin beta3 Leu33Pro polymorphism and risk of hip fracture: 25 years follow-up of 9233 adults from the general population. Pharmacogenet Genomics. 2007;17(1):85-91.

\section{Publish your work in this journal}

Pharmacogenomics and Personalized Medicine is an international, peer-reviewed, open access journal characterizing the influence of genotype on pharmacology leading to the development of personalized treatment programs and individualized drug selection for improved safety, efficacy and sustainability. This journal is indexed on the
American Chemical Society's Chemical Abstracts Service (CAS). The manuscript management system is completely online and includes a very quick and fair peer-review system, which is all easy to use. Visit http://www.dovepress.com/testimonials.php to read real quotes from published authors.

Submit your manuscript here: http://www.dovepress.com/pharmacogenomics-and-personalized-medicine-journal 